\section{Isolation and characterization of microsatellites in iris}

\section{JOHN M. BURKE and MICHAEL L. ARNOLD}

Deparement of Genetics, University of Georgia, Athens, GA 30602-7223, USA

Correspondence: M. L. Arnold. Fax: +1-706-542-3910; E-mail:

arnold@dogwood.botany.uga.edu

Keywords: Iris, Louisiana irises, hybridization, microsatellites, paternity

Received 13 February 1999; revision accepted 4 March 1999

The Louisiana iris species complex consists of three widespread species (Iris fulva Ker-Gawler, I. hexagona Walter and I. brevicaulis Raf.; Viosca 1935) and a rare diploid hybrid species (I. nelsonii Rand.). While these species have relatively wide ranges (with the exception of $I$. nelsonii) and distinct ecological preferences, they occur sympatrically in southern Louisiana where interspecific matings have led to the production of hybrid populations (e.g. Viosca 1935; Arnold et al. 1990). Although the ecology, taxonomy and evolution of the Louisiana irises have been studied for over 50 years, direct estimates of gene flow, mating patterns and hybrid fitness in natural populations are lacking. To this end, we developed a suite of five microsatellite loci from two species of Louisiana iris, I. brevicaulis and I. fulva, that will allow us to take a paternity-based approach to the study of these phenomena in natural Iris populations.

Cloning and screening procedures followed the methods of Aldrich et al. (1998). Total genomic DNA was isolated from fresh leaf tissue of a single I. brevicaulis and a single I. fulva individual using the DNeasy Plant Mini Kit (QIAGEN). The DNA was digested with $\mathrm{MboI}$ and size selected by excising $300-700$ bp fragments from a $2 \%$ agarose gel (QIAquick Gel Extraction Kit, QIAGEN). The size-selected DNA fragments were then ligated into the BamHI site of a lambda vector (ZAP Express, Stratagene) and packaged (ZAP Express Gigapack III Gold packaging extract, Stratagene). The packaged libraries were used to infect XL1-Blue Escherichia coli cells and plated in top agar. Plaques were lifted with nylon membranes (Hybond $\mathrm{N}+$, Amersham) and screened with a $\left[\gamma^{32} \mathrm{P}\right]$ dATP end-labelled (GA) ${ }_{10}$ probe. Seventeen plates carrying $\approx 1000$ plaques/plate were screened for each species. Candidate plaques were picked and rescreened at a lower density to minimize false positives. A total of 27 I. brevicaulis and 26 I. fulva clones were amplified using the M13 forward and reverse primers, purified with the High Pure PCR Product Purification Kit (Boehringer Mannheim) and sequenced on an automated sequencer using the ABI Dye Terminator Prism Kit (ABI/Perkin-Elmer). Primers were designed for eight $I$. brevicaulis and seven $I$. fulva loci. Of these, three of the I. brevicaulis and two of the I. fulva primer pairs produced amplification products that were both interpretable and polymorphic in at least one of the species (Table 1).

Polymerase chain reactions were performed in $20 \mu \mathrm{L}$ volumes containing $50 \mathrm{ng}$ of genomic DNA, buffer [50 mM Tris- $\mathrm{HCl} \mathrm{pH}$ 8.0, $100 \mathrm{~mm} \mathrm{NaCl}, 0.1 \mathrm{~mm}$ EDTA, $1 \mathrm{~mm}$ DTT, $50 \%$ glycerol and $1 \%$ Triton X-100), $2.0 \mathrm{~mm} \mathrm{MgCl}_{2}, 8$ pmol of each primer, $125 \mu \mathrm{M}$ of each dNTP and 0.8 units of Taq DNA polymerase (Promega)]. Amplification conditions consisted of an initial $2 \mathrm{~min}$ denaturation at $94^{\circ} \mathrm{C}$, followed by 30 cycles of $94{ }^{\circ} \mathrm{C}$ for $1 \mathrm{~min}, 56-62{ }^{\circ} \mathrm{C}$ for $1 \mathrm{~min}$ and $72{ }^{\circ} \mathrm{C}$ for $1 \mathrm{~min}$. The 30 cycles were followed by $5 \mathrm{~min}$ at $72{ }^{\circ} \mathrm{C}$. Reactions were carried out in a Perkin-Elmer Cetus 9810 Thermal Cycler. Polymorphisms were detected by end-labelling one primer with $\left[\gamma^{32} \mathrm{P}\right]-\mathrm{dATP}$ using $\mathrm{T} 4$ polynucleotide kinase $(1 \mu \mathrm{Ci}$ per $5 \mathrm{pmol}$ of primer), resolving fragments on $6 \%$ polyacrylamide gels and visualizing them by autoradiography.

The five primer pairs produced interpretable, polymorphic amplification products in I. brevicaulis. In contrast, IB141 consistently failed to amplify in $I$. fulva, even after multiple attempts to redesign the primers, and IF061 amplified as many as four alleles in each $I$. fulva individual, suggesting that this locus has been duplicated in this species. In order to assess allelic variability at all five loci, we screened $41 \mathrm{I}$. brevicaulis and 19 I. fulva individuals collected from natural populations of these two species. The number of alleles ranged from

Table 1 Characteristics of five microsatellite loci cloned from two species of Louisiana iris, including locus name, GenBank Accession no., primer sequences, repeat motif, annealing temperature, size of the sequenced allele and total number of alleles from the two species combined. The number of alleles, observed heterozygosity and expected heterozygosity are reported for each locus in each species separately

\begin{tabular}{|c|c|c|c|c|c|c|c|c|c|c|c|}
\hline \multirow{2}{*}{$\begin{array}{l}\text { Locus } \\
\text { (Accession) }\end{array}$} & \multirow[b]{2}{*}{ Sequence $\left(5^{\prime}-3^{\prime}\right)$} & \multirow[b]{2}{*}{ Repeat } & \multirow{2}{*}{$\begin{array}{l}T_{\mathrm{a}} \\
\left({ }^{\circ} \mathrm{C}\right)\end{array}$} & \multirow[b]{2}{*}{$\begin{array}{l}\text { Size } \\
\text { (bp) }\end{array}$} & \multirow{2}{*}{$\begin{array}{l}\text { Alleles } \\
\text { (total) }\end{array}$} & \multicolumn{3}{|c|}{ I. brevicaulis } & \multicolumn{3}{|l|}{ I. fulva } \\
\hline & & & & & & Alleles & $H_{\mathrm{O}}$ & $H_{\mathrm{E}}$ & Alleles & $H_{\mathrm{O}}$ & $H_{\mathrm{E}}$ \\
\hline IB025 & GATCTCACATCGTTTGGTC & $(\mathrm{GA})_{27}$ & 56 & 104 & 25 & 17 & 0.71 & 0.91 & 13 & 0.94 & 0.90 \\
\hline (AF124505) & CGATAACCCAACTTCACTAC & & & & & & & & & & \\
\hline IB141 & CTGAACCACCGGTCACAAG & $(\mathrm{GA})_{15}$ & 56 & 156 & 12 & 12 & 0.90 & 0.83 & - & - & - \\
\hline (AF124506) & GAAGCCATGTTGAAGTTGTCC & & & & & & & & & & \\
\hline IB145 & TGTTGCGGGATTAAGGAGAC & $(\mathrm{GA})_{15}$ & 56 & 164 & 22 & 19 & 0.83 & 0.92 & 10 & 0.76 & 0.83 \\
\hline (AF124507) & CAACGAGAAGAATTATCCGAAAG & & & & & & & & & & \\
\hline IF061 & TTGGGACAACCATTTGAGGA & $(\mathrm{GA})_{24}$ & 62 & 235 & 16 & 16 & 0.92 & 0.90 & - & - & - \\
\hline (AF124508) & CGCCGACAAGACCCTGAC & & & & & & & & & & \\
\hline IF073 & TGGCTCTACCTTCACCACAAC & $(\mathrm{GA})_{19}$ & 58 & 195 & 14 & 8 & 0.60 & 0.83 & 9 & 0.95 & 0.85 \\
\hline (AF124509) & CCGAACCCAGAATGGAAGTG & & & & & & & & & & \\
\hline
\end{tabular}


8 to 17 in $I$. brevicaulis and from 9 to 13 in I. fulva (Table 1 ). Overall, there was a total of 12-25 alleles per locus in the two species combined. In all cases, expected heterozygosities were quite high, ranging from 0.83 to 0.92 in I. brevicaulis and from 0.83 to 0.90 in I. fulva. Only two of the five loci (IB141 and IF061) conformed to Hardy-Weinberg expectations in $I$. brevicaulis when tested with the probability test of GENEPOP (Raymond \& Rousset 1995), whereas all three loci assayed in I. fulva were consistent with Hardy-Weinberg expectations. The significant heterozygote deficits $(P<0.05)$ at IB025, IB145 and IF073 in I. brevicaulis could be due to the presence of null alleles. Alternatively, these deviations could be an artefact of our sampling strategy. That is, we could have created an apparent heterozygote deficit (i.e. a Wahlund effect) by sampling a substructured I. brevicaulis population across which allele frequencies at these three loci were strongly differentiated. The relatively high level of variation described above, combined with the fact that three of our five loci are informative in both I. brevicaulis and I. fulva, suggests that these markers are well suited for paternity studies in hybrid Iris populations.

\section{Acknowledgements}

We thank P. Aldrich, D. Erickson, K. Hufford and G. Kochert for their assistance. This work was supported by NSF Grant DEB-9703853 (MLA) and NSF/USDA/DOE Training Grant BIR9220329 (JMB).

\section{References}

Aldrich PR, Hamrick JL, Chavarriaga P, Kochert G (1998) Microsatellite analysis of demographic genetic structure in fragmented populations of the tropical tree Symphonia globulifera. Molecular Ecology, 7, 933-944.

Arnold ML, Bennett BD, Zimmer EA (1990) Natural hybridization between Iris fulva and I. hexagona: patterns of ribosomal DNA variation. Evolution, 44, 1512-1521.

Raymond M, Rousset F (1995) GENEPOP (Version 1.2): a population genetics software for exact tests and ecumenicism. Journal of Heredity, 86, 248-249.

Viosca P Jr (1935) The irises of southeastern Louisiana: a taxonomic and ecological interpretation. Bulletin of the American Iris Society, $57,3-56$. 